\title{
O QUE É FILOSOFIA DA PSICANÁLISE?
}

\author{
Luiz Roberto Monzani (Unicamp)* \\ luiz.monzani@pq.cnpq.br
}

Resumo: A questão que se põe é: o que se entende pela expressão Filosofia da Psicanálise? Pode-se, em primeiro lugar, ficar espantado com essa pergunta, porque, ao menos, genericamente, essa expressão deve possuir um significado muito aparentado às expressões tais como: filosofia das matemáticas, filosofia da física, filosofia da biologia etc, a respeito do que não faltam exemplos de trabalhos sérios e bem sucedidos. Pensando as coisas assim, a filosofia da psicanálise, assim como a filosofia das matemáticas etc., nada mais seria que um ramo, uma espécie dessa disciplina mais geral que denominamos filosofia da ciência, que consiste, em linhas gerais, em se tentar saber qual é o modo próprio e específico que cada disciplina tem de estabelecer suas teses. Qual, por exemplo, o papel da observação, da experiência, do raciocínio etc. Como essa disciplina encadeia suas proposições, como ela procura fundamentá-las. $\mathrm{O}$ que tal ou tal disciplina entende por verdade, por proposição verdadeira. Enfim, o filósofo endereça às diferentes ciências questões do tipo: qual o seu regime de provas e validação? Qual o papel da experimentação e das hipóteses? Há uma adequação entre as proposições que ela coloca e aquilo através do qual procura estabelecê-las? Esses são exemplos de questões colocadas por isso que entendemos correntemente por filosofia das ciências. É o que examinaremos nesse artigo.

Palavras-chave: Filosofia, Psicanálise, Filosofia da ciência.

\section{1- A questão que se põe é: o que se entende pela expressão Filosofia da Psicanálise?}

\footnotetext{
*Luiz Roberto Monzani é professor Adjunto da Universidade Estadual de Campinas, Campinas, Brasil e pesquisador do CNPq.
} 
2- Pode-se, em primeiro lugar, ficar espantado com essa pergunta, porque, ao menos, genericamente, essa expressão deve possuir um significado muito aparentado às expressões tais como: filosofia das matemáticas, filosofia da física, filosofia da biologia etc., a respeito do que não faltam exemplos de trabalhos sérios e bem sucedidos.

3- Pensando as coisas assim, a filosofia da psicanálise, assim como a filosofia das matemáticas etc., nada mais seria que um ramo, uma espécie dessa disciplina mais geral que denominamos filosofia da ciência, que consiste, em linhas gerais, em se tentar saber qual é o modo próprio e específico que cada disciplina tem de estabelecer suas teses. Qual, por exemplo, o papel da observação, da experiência, do raciocínio etc. Como essa disciplina encadeia suas proposições, como ela procura fundamentá-las. O que tal ou tal disciplina entende por verdade, por proposição verdadeira. Enfim, o filósofo endereça às diferentes ciências questões do tipo: qual o seu regime de provas e validação? Qual o papel da experimentação e das hipóteses? Há uma adequação entre as proposições que ela coloca e aquilo através do qual procura estabelecê-las? Esses são exemplos de questões colocadas por isso que entendemos correntemente por filosofia das ciências.

4- A filosofia da ciência visa, portanto, uma investigação metodológica e procura saber se os resultados de uma determinada disciplina estão ou não de acordo com um determinado critério de verdade, freqüentemente clássico. Se a resposta for positiva, então estaremos frente a um discurso que pode ser rotulado de científico. Caso 
contrário, estaríamos frente a uma pseudociência ou frente a algum outro tipo de saber que não se submete ao figurino pressuposto.

5- Embora eu considere legítimo e válido esse tipo de atividade, todo o problema está em que esse tipo de procedimento é muito limitado, e diferentes ciências, ou mesmo a mesma ciência em diferentes estágios, dificilmente se amoldam a esses critérios externos. Tal é o caso da física contemporânea, ciência canônica por excelência, na qual a obra de G. Bachelard mostrou a precariedade desses critérios. Na verdade - eu tenho impressão -, esse procedimento funciona bem pra disciplinas constituídas segundo um certo modelo, o que, modernamente, parece ser cada vez mais raro. Eu repito, não está em meus propósitos negar o direito de quem quer que seja de utilizar tais procedimentos. Apenas quero realçar suas limitações, aquilo que vejo como suas limitações, e apontar outras possibilidades.

6- No caso da psicanálise (Freudiana) isso fica patente e gritante. Em primeiro lugar, porque é difícil dizer que a psicanálise é uma disciplina já constituída. De uma certa maneira, em segundo lugar, isso que eu estou afirmando a respeito da psicanálise, suspeito que seja válido para um bom número de disciplinas que enfeixamos sob a designação geral de ciências humanas. A idéia talvez mais correta seja a de que, na melhor das hipóteses, são disciplinas que estão se fazendo, e o resultado disso é muito difícil de se saber. 
7- Por isso mesmo que talvez a idéia canônica de filosofia da ciência freqüentemente se aplique mal a esses domínios e, em espécie, à psicanálise. Deve haver um certo tipo de abordagem que também se interesse pelos modos de procedimento de uma disciplina que não se reduza a isso e que, sobretudo, não queira instaurar um tribunal em que essas diferentes formas discursivas tenham de humildemente depositar aos seus pés seus "títulos" de cidadania, para que sejam julgados segundo regras prédeterminadas.

8- Um primeiro grupo de abordagens seria tomar o discurso psicanalítico como o primeiro "corpus" de textos (a obra de Freud, por exemplo) e tentar estabelecer um conjunto de genealogias conceituais que influenciaram e mesmo determinaram, em certa medida, a constituição desse discurso, sem se preocupar com a verdade ou falsidade desse mesmo discurso. Pode-se, por exemplo, tentar retraçar toda a trama conceitual que levou de Charcot a Freud, com relação ao problema da história. Ou, então, tentar examinar como certas "redes" ou "grades" conceituais (por exemplo, os ideais científicos de Helmholtz, Fechner, Bruckner que seguramente Freud conhecia) influenciaram a ótica freudiana na sua leitura dos fenômenos psicopatológicos. Os exemplos não faltam e existem inúmeros trabalhos nessa linha, de excelente qualidade.

9- Pode-se também, e esse é um outro tipo de trabalho, tomar a teoria psicanalítica como uma rede discursiva, tratála assim, como um tecido de significações que vale a pena ser explicitado, comentado, discutido e interpretado. 
Podemos, então, ler Freud, não preocupados com a verdade da doutrina, mas sim preocupados apenas em como estabelece, propõe, abandona, alarga ou estreita os significados de diferentes conceitos no interior da teoria, como, por exemplo, a teoria da sedução, o complexo de Édipo ou a pulsão de morte. Tratar-se-ia, neste caso, de uma leitura interna do texto, do discurso que procuraria decifrar o seu encadeamento, seus embates, suas contradições etc., etc.

10- Vislumbro ainda um terceiro tipo de leitura, talvez a mais interessante. Pelo menos para mim é a mais interessante. Aqui, mais uma vez, penso que esse tipo de leitura é mais frutífera e fecunda para a psicanálise e as ciências humanas. Os pressupostos desse terceiro tipo de leitura estão totalmente enraizados no segundo tipo que acabei de mencionar. Parte-se da idéia de que cada disciplina produz um determinado saber que tem seu contorno e sua especificidade própria. Enfim, desse ponto de vista, abandona-se o ideal unitário de ciência, pelo menos provisoriamente, e seu correlato: o de que só existe um tipo de verdade (o figurino que mencionei acima). A partir daí [e realizada essa leitura interna preconizada no segundo tipo (encadeamento das teses, postulados, conseqüências etc.)] esse terceiro tipo de leitura procurará examinar e demarcar o conjunto dos critérios próprios e específicos de validação da disciplina em questão, e qual o critério e a idéia de verdade que daí brotam. Trata-se, portanto, neste último caso, de inverter o procedimento tradicional da filosofia da ciência, que parte de uma prédeterminada idéia de verdade, e se pergunta se as diferentes 
disciplinas que vão desfilando frente a ela (matemática, física, biologia, psicanálise etc.) se adequam ou não a esse modelo pré-estabelecido. Quer dizer, ao invés de procurar impor de fora, como uma camisa-de-força, certos critérios que se julgam válidos para toda e qualquer disciplina que se queira apresentar como ciência, procura-se, neste outro caso, a especificidade do modo de produção discursiva, quais os critérios próprios e específicos desse particular regime de validação.

11- A questão que se coloca agora, por exemplo, não é: a psicanálise é uma ciência? Mas esta outra: que tipo de racionalidade nos traz a psicanálise? Já que, de uma vez por todas, a psicanálise se enquadra muito pouco dentro da concepção tradicional de ciência. Já que esse tipo de pergunta foi feita no próprio interior da física contemporânea, como mostrou Bachelard, por que não aplicá-la a outros domínios? É claro que a questão mais geral, que está por trás dessa que enunciei, é a questão de se saber até onde a proliferação desses novos discursos, desses novos saberes, não nos convida a repensar a noção de verdade que, talvez, seja ela também, na sua forma canônica, algo datado e fruto de um conjunto de avaliações sobre o real, o conhecimento, o discurso verdadeiro etc. que exatamente essas novas disciplinas nos convidam a repensar?

12- Daí, sobretudo, é de onde eu vejo o interesse de uma filosofia da psicanálise: não para se saber se é uma ciência ou não, mas sim porque ela nos faz repensar os nossos pressupostos mais enraizados. 
13- Se se quer dar nome aos bois - mas essa questão não tem grande importância -, o primeiro tipo de leitura que eu apontei - o traçado dessa genealogia conceitual pertenceria à história das ciências ou dos saberes; a segunda, essa leitura interna, pertenceria à reconstituição discursiva, algo como uma análise dos procedimentos e encadeamentos discursivos; e o último trabalho eu denominaria epistemologia da psicanálise.

14- Nessa linha de raciocínio, trata-se, como diz muito bem o professor Bento Prado Jr., de uma via de duas mãos; se a filosofia, se o discurso filosófico pode e deve colocar algumas questões ao discurso psicanalítico, sem dúvida alguma a psicanálise coloca alguns problemas centrais para a filosofia.

15- Não vou levar em consideração certas apropriações indevidas que o discurso filosófico fez algumas vezes da teoria e dos conceitos psicanalíticos porque esse tipo de trabalho jamais deu certo. De resto, limito-me apenas em apontar isso porque a crítica dessas tentativas já foi feita, e muito bem feita, por diversos autores. Ainda, eu indicaria para vocês dois belos artigos do professor Bento Prado Jr., o primeiro deles intitulado: "Auto-reflexão ou interpretação sem sujeito..." (incluído no livro Alguns ensaios ${ }^{1}$ ) e outro: "Entre o alvo e o objeto do desejo..." (que está na coletânea Filosofia da Psicanálise ${ }^{2}$ ) onde, respectivamente, o professor Bento critica com muita pertinência as apropriações ou más leituras que Habermas e Marcuse fizeram da teoria freudiana. 
16- Mas, deixando isso de lado, eu repito, a teoria psicanalítica não deixa de colocar problemas para o discurso filosófico, tais como (estou citando aleatoriamente) o problema da gênese e constituição do aparelho cognitivo. Há inúmeras pistas e problematizações em Freud. Outro problema: o da origem e o papel da consciência moral tanto na esfera do sujeito singular, como também de seu papel nas séries coletivas. Por outro lado, existe, sem sombra de dúvida, em Freud, senão uma teoria, pelo menos preciosas indicações sobre os fatores da hominização, um esboço da gênese histórica da sociabilidade e dos fatores psíquicos determinantes dessa mesma sociabilidade.

Por último, mais um exemplo, talvez o mais significativo e importante, para ilustrar o quanto estamos tateando. Quem estudou seriamente a obra de Freud sabe perfeitamente que o conceito, ou melhor, a concepção de sujeito sofreu, em suas mãos, uma transformação de monta. Mas o que significou isso? Destronamento do cogito e de seus privilégios? Em certa medida, sim. Ponto final e definitivo nas "filosofias da consciência"? Problemático, já que o próprio Freud afirmava que a consciência é o nosso único farol nas trevas da psicologia profunda. Isso sem falar no famoso adágio: $W_{o}$ es war, soll ich werden. Descentramento radical do sujeito e determinação pela instância do "outro"? Com certeza, sim. Mas o que significa exatamente isso? Qual o sentido dessa transformação e quais as suas conseqüências? A bem da verdade, ainda não sabemos direito, e é por isso que, entre muitas outras 
razões, amemos Freud ou não, sua leitura nos é obrigatória e indispensável.

\section{NOTAS}

1 Prado Jr., Bento. Alguns Ensaios. São Paulo: Paz e Terra, 2000.

2 Prado Jr. Bento. Entre o alvo e o objeto do desejo: Marcuse, crítico de Freud. In: Filosofia e Psicanálise. São Paulo: Brasiliense, 1991. 